\section{The Impact of Lateral Incisor Dimensions on Smile Perception - A Study of Patients' Tolerance for Deviation from the Ideal}

\section{Abstract}

Background and aim: The lateral incisor is one of the most commonly associated anterior teeth with being congenitally missing or affected by Microdontia. The purpose of this research was to evaluate the influence of variations in the position, proportion and angulation of lateral incisors on patients' perception towards an ideal smile.

Methodology: One hundred and ninety eight subjects between 15 and 35 years of age, in Riyadh, Saudi Arabia, were asked to fill out a brief Questionnaire. Thereafter, using the means of a PowerPoint Presentation, the participants were shown a series of photographs of an ideal smile in which the lateral incisors were altered within set parameters. The participants identified which image, within each sequence, was most esthetic in their opinion.

Results and conclusions: Most of the participants preferred shorter $(-2.22 \mathrm{~mm})$ and wider $(1.82 \mathrm{~mm})$ lateral incisors, compared with the ideal image. A majority of participants preferred that the long axis of the lateral incisor be parallel to that of the central incisor. $40.4 \%$ of the population tolerated a mesial $5^{\circ}$ tilt and only $11.6 \%$ tolerated a distal $5^{\circ}$ tilt. Female tolerance towards variations in height and width were significantly less than their male counterparts. Participants' tolerance for shorter and wider lateral incisors, compared with the ideal, was seen when these parameters were assessed individually. Majority of the participants tolerated $0^{\circ}-5^{\circ}$ of mesial tilting for the lateral incisor.

Keywords: Dental esthetics; Lateral incisors; Patient perception; Smile

\section{Sharat Chandra Pani, Rohit Anthony Fernandez, Rachad Ihsan Kudsi, Farid Farouk Elkhawly, Ammar Naim AlBatran and Mustafa Abdulrahman Nasser M}

\author{
Riyadh Colleges of Dentistry and Pharmacy, \\ Riyadh, Saudi Arabia
}

Corresponding author: Sharat Chandra Pani

\section{戸 sharatpani@hotmail.com}

Riyadh Colleges of Dentistry and Pharmacy, Saudi Arabia.

Tel: $966-920000182$

Citation: Pani SC, Fernandez RA, Kudsi RI, et al. The Impact of Lateral Incisor Dimensions on Smile Perception - A Study of Patients' Tolerance for Deviation from the Ideal. Periodon Prosthodon. 2016, 2:1.

\section{Introduction}

The role of the lateral incisor in the design and esthetics of a smile is a topic of importance. There have been studies to show that the shape, size, angulation and position of the lateral incisor may affect the esthetics of a smile [1-3]. Furthermore, the relationship of the lateral incisor to the central incisor and canine, often called the 'Golden Proportion', has also been shown to play a role in how the smile is perceived [3].

However, patient perception is subjective; a lateral incisor may be perceived as ideal to one group of patients and unesthetic to others. Factors such as gender and ethnicity have been previously studied [4]. This warrants that the dentist be well aware of the patients' needs to fulfill treatment objectives. A proper discussion between the dentist and the patient is paramount in identifying the patient's perception to his/her final ideal smile.
The ideal smile for a particular population may not suit another. There have been studies that have shown that the perceptions of the certain components of the smile vary between different populations. There has also been research that suggests that the perception of esthetics by the population is influenced by factors such as cultural influences, portrayal in the media. There is little previous literature on the influence of the position, proportion and angulation of the lateral incisor on patients' perception of an ideal smile among Saudi patients.

The aim of this research is to evaluate the effect of variations in the position, proportion and angulation of lateral incisors on patients' perception towards an ideal smile.

\section{Materials and Methods}

Ethical approval for the study was obtained from the research 
center of the Riyadh Colleges of Dentistry and Pharmacy and the project was assigned the number FIRP/2014/107.

A photograph of an ideal smile was obtained from a female volunteer, accompanied with a signed informed consent. This photo was then modified, using Adobe Photoshop CS5 (Adobe Systems, USA), to meet previously set criteria for an ideal smile, with regards to gingival display, buccal corridor, arch shape and tooth display [3-5].

The software was then used to generate filmstrips of images which successively varied along three parameters, namely:

a) Position of the lateral incisal edge in relation to the line joining the incisal edge of the central incisor and the tip of the canine i.e., the height of the lateral incisor.

b) Proportion of the width of the lateral incisor with relation to the central incisor and canine.

c) Angulation of the lateral incisor along the long axis of the tooth, i.e., mesial and distal tilting of the lateral incisor.

To eliminate the possibility of biases from patients, the filmstrips were designed in such a way that each parameter had both increasing and decreasing arrangement of images. For the variations in height of the lateral incisor a series of 42 images were generated with varying lengths about the ideal. Likewise, for the variations in width of the lateral incisor a series of 34 images were generated. For mesial and distal inclinations, 6 images each were generated with tilts given to the lateral incisor at 5, 10, 15, 20 and 25 degrees respectively.

These images from each filmstrip were placed sequentially in a PowerPoint Presentation (MS PowerPoint, Microsoft corp. Santa Alta CA) such that each subsequent slide would display one unit change within a set parameter.

Patients living in Riyadh, Saudi Arabia, between the ages of 15 and 35 years with esthetic interests were selected for the study. The demographic data of these participants were collected via a brief Questionnaire. The master PowerPoint presentation was then showcased to them to obtain their perception of an esthetic smile while glancing through the variations made for the lateral incisor along all three parameters of vertical position, horizontal proportion and mesial and distal angulation.

\section{Results}

A total of 198 participants (92 male and 106 female) aged between 15 and 35 years participated in the study. The mean age of the population was 25.54 (SD \pm 8.1 ) years, with males $(26.7$ \pm 8.1 years) being older than females ( $21.88 \pm 3.5$ years). Effort was made to include participants from all educational and socioeconomic backgrounds (Table 1).

When the height of the lateral incisor was assessed it was found that the overall tolerance for variation ranged between $1.1 \mathrm{~mm}$ taller and $2.22 \mathrm{~mm}$ shorter than the ideal height. Tolerance levels for variation in height were significantly lower for female respondents than that for the male respondents (Table 2).

When the width of the incisor was analyzed it was seen that the overall tolerance for the change in the width of the incisors ranged from $1.82 \mathrm{~mm}$ wider than to $1.45 \mathrm{~mm}$ narrower than the ideal. Here again the tolerance levels of the female respondents were significantly lower than that of their male counterparts (Table 2).

The tolerance of the population for deviation in the angle of the tooth to the long axis was measured in degrees. The female respondents had significantly lower tolerance towards deviation when compared to males. While the tolerance for mesial deviation in the angulation of the lateral incisors extended up to 15 degrees for males, this tolerance was limited to 5 degrees for females. The distal deviation had no tolerance beyond 5 degrees. On the distal deviation parameter, the tolerance for deviation was significantly lower than those who had no tolerance for any deviation (Table 3).

\section{Discussion}

The lateral incisor forms a key part of the smile and smile perception with authors pointing out that variations in the dimensions of the incisor can influence smile perception [6]. The aim of this study was to test the tolerance limits for a population aged between 15 and 35 years for variations in the several different dimensions of the lateral incisor (Figures 1-3).

There have been several methods used to test variation in shapes and sizes of facial and dental proportions. While conventional studies have used sets of pictures that depict variations in size in terms of a graded scale [5,7-9], others have instead opted to use the filmstrip with definite measurements between photographs [10]. In this study we decided to use the filmstrip as it would allow us to develop a quantifiable limit, in both millimeters and degrees, to determine the tolerance of the population towards changes in the vertical and horizontal dimensions, as well as the mesial or distal inclinations of the lateral incisors.

The lateral incisor is a commonly missing permanent tooth and is also a tooth that is frequently associated with Microdontia (peg shaped laterals); making it important for dentists to understand factors influencing patient satisfaction with restorations placed on the tooth [11]. This was the reason that we chose to study the acceptable limits of patient tolerance for changes in height, width and angulation of the lateral incisors.

The width of the lateral incisor is of concern to both orthodontists and restorative dentists [12]. We found that our sample had a mean tolerance of $3.27 \mathrm{~mm}$ about an ideal photograph (1.82 $\mathrm{mm}$ wider to $1.45 \mathrm{~mm}$ narrower). This is an interesting finding as it suggests that restorative dentists who choose to reshape canines as lateral incisors have to greatly reduce the canine before it is acceptable to the average patient. This is in keeping with the findings of Brough et al. who suggest that the dentist who chooses to substitute a lateral incisor with a missing canine should be prepared to make use of camouflaging tools such as shade and depth [13]. The fact that females had a significantly lower tolerance than males, for changes in width of the lateral incisor, is in keeping with several studies on dental esthetics that have shown that females have a higher and more demanding esthetic standard than males $[1,6,9,10,14]$.

The incisal edge forms a critical component of the smile evaluation with most authors agreeing that the ideal lateral 
Table 1 Socio-demographic Profile of the population.

\begin{tabular}{|c|c|c|c|c|c|}
\hline & & \multicolumn{4}{|c|}{ Gender } \\
\hline & & \multicolumn{2}{|c|}{ Male } & \multicolumn{2}{|c|}{ Female } \\
\hline & & Count & Column N\% & Count & Column N \% \\
\hline \multirow{6}{*}{ Family income } & $<5000$ SR & 16 & $17.4 \%$ & 2 & $1.9 \%$ \\
\hline & $5000-10,000 S R$ & 73 & $79.3 \%$ & 5 & $4.7 \%$ \\
\hline & $10,000-20,000$ SR & 1 & $1.1 \%$ & 12 & $11.3 \%$ \\
\hline & $20,000-30,000$ SR & 1 & $1.1 \%$ & 26 & $24.5 \%$ \\
\hline & $40,000-60,000 S R$ & 1 & $1.1 \%$ & 30 & $28.3 \%$ \\
\hline & $>60,000$ & 0 & $0.0 \%$ & 31 & $29.2 \%$ \\
\hline \multirow{4}{*}{ Education level } & Did not complete High School & 3 & $3.3 \%$ & 0 & $0.0 \%$ \\
\hline & High School Graduate & 39 & $42.4 \%$ & 86 & $81.1 \%$ \\
\hline & Basic College Degree & 49 & $53.3 \%$ & 17 & $16.0 \%$ \\
\hline & Advanced College Degree & 1 & $1.1 \%$ & 3 & $2.8 \%$ \\
\hline
\end{tabular}

Table 2 The tolerance of variations of the Height and Width of the Lateral Incisor.

\begin{tabular}{|c|c|c|c|c|}
\hline & Gender & $\begin{array}{l}\text { Mean Tolerance } \\
\text { Increasing }\end{array}$ & $\begin{array}{l}\text { Mean Tolerance } \\
\text { decreasing }\end{array}$ & Sig* \\
\hline \multirow{3}{*}{$\begin{array}{l}\text { Tolerance in Height (in } \mathrm{mm} \text { ) } \\
\text { Measured as deviation from Ideal }\end{array}$} & Male & 1.2 & -2.33 & \multirow{3}{*}{$0.021 * *$} \\
\hline & Female & 0.9 & -2.13 & \\
\hline & Overall & 1.1 & -2.22 & \\
\hline \multirow{3}{*}{$\begin{array}{l}\text { Tolerance in Width (in } \mathrm{mm} \text { ) } \\
\text { Measured as deviation from Ideal }\end{array}$} & Male & 2.63 & -1.93 & \multirow{3}{*}{$0.001 * *$} \\
\hline & Female & 1.34 & -1.02 & \\
\hline & Overall & 1.82 & -1.45 & \\
\hline
\end{tabular}

${ }^{*}$ Calculated using the student's $t$ test; **Difference significant at $p<0.05$

Table 3 Tolerance of the sample population for changes in angulation in the lateral incisor.

\begin{tabular}{|c|c|c|c|c|}
\hline & & Male & Female & Sig* \\
\hline \multirow{5}{*}{$\begin{array}{c}\text { Mesial Deviation in } \\
\text { degrees }\end{array}$} & 0.00 & 57 & 58 & \multirow{5}{*}{$<0.001 * *$} \\
\hline & 5.00 & 32 & 48 & \\
\hline & 10.00 & 1 & 0 & \\
\hline & 15.00 & 2 & 0 & \\
\hline & Total & 92 & 106 & \\
\hline \multirow{3}{*}{$\begin{array}{c}\text { Distal Deviation in } \\
\text { degrees }\end{array}$} & 0.00 & 73 & 102 & \multirow{3}{*}{$<0.001^{* *}$} \\
\hline & 5.00 & 19 & 4 & \\
\hline & Total & 92 & 106 & \\
\hline
\end{tabular}

*Calculated using the Chi-Square test; ${ }^{* *}$ Difference significant at $p<0.05$.

incisor should be $2 \mathrm{~mm}$ above the occlusal plane. In our study we found that the population had a lower tolerance for variations in height than width. The mean tolerated height, acceptable by the patients, ranged from $1.1 \mathrm{~mm}$ taller to $2.22 \mathrm{~mm}$ shorter than the ideal picture. Movement towards the occlusal plane was considered unacceptable by most patients. This finding coincides with previously reported findings that suggest that the balance between the vertical dimensions of the central and lateral incisors is critical for a smile to be perceived as esthetic $[6,9]$.

The angulation of the lateral incisor is a key component of esthetics with Prosthodontic texts suggesting that a mesial angulation of the lateral incisor offers a more feminine look to the face [15]. This could explain why a significant number of females and a sizeable number of males found the 5 degree mesial angulation of the lateral incisor to be esthetically acceptable. It must be noted, however, that any further mesial angulation was unacceptable to a significant majority of the population. This is in keeping with the findings of Brunzel et al. who showed through digital manipulation techniques that minor angulations of the central or lateral incisors could actually enhance the esthetic perception of lay persons [1].

It is worthy to note that distal angulation of the lateral incisor was not tolerated beyond 5 degrees for both genders. It was seen that a majority of the respondents preferred no distal deviation i.e., the ideal image, over any distal deviation to the lateral incisor.

While the results of this study demonstrate that the lateral incisors play an important role in esthetics, it is limited by certain factors such as a relatively small sample size and lack of proportional sampling. Further studies that address these shortcomings are needed to establish clearly the extent to which the lateral incisor's dimensions and position can alter smile perception in young adults.

\section{Conclusion}

The results of this study seem to indicate that the population studied has their own unique preferences and tolerances of the size, position and angulation of the lateral incisor. Within the limitations of this study we can conclude that changes in the dimensions and angulation of the lateral incisor can influence the patients' perception of their smile. Tolerances for variations from the ideal dimensions vary with gender. 


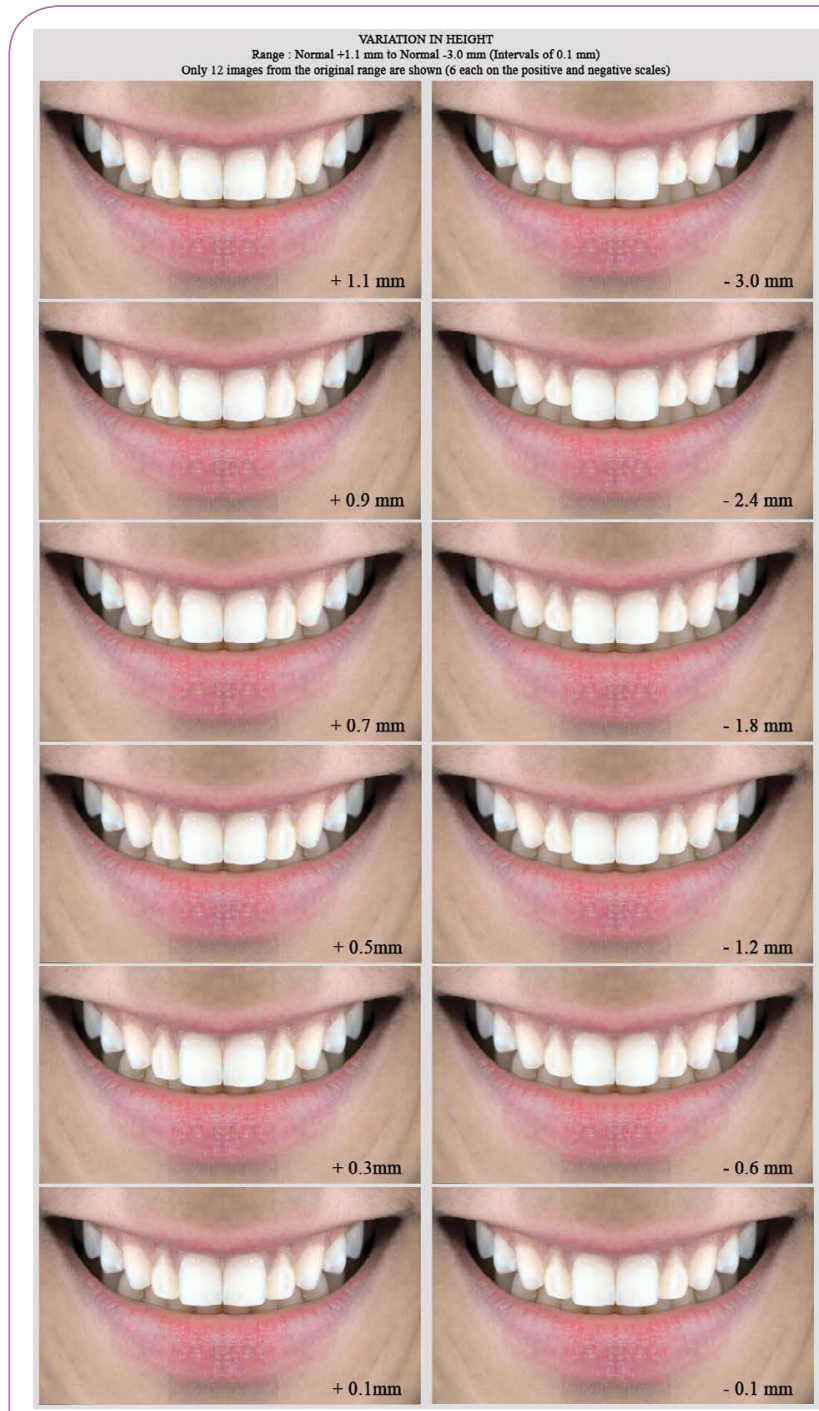

Figure 1 Sample of the pictures for Variation in Height of the lateral incisors (the pictures were presented to the patients in the form of a power point slideshow with variations of $0.1 \mathrm{~mm})$.

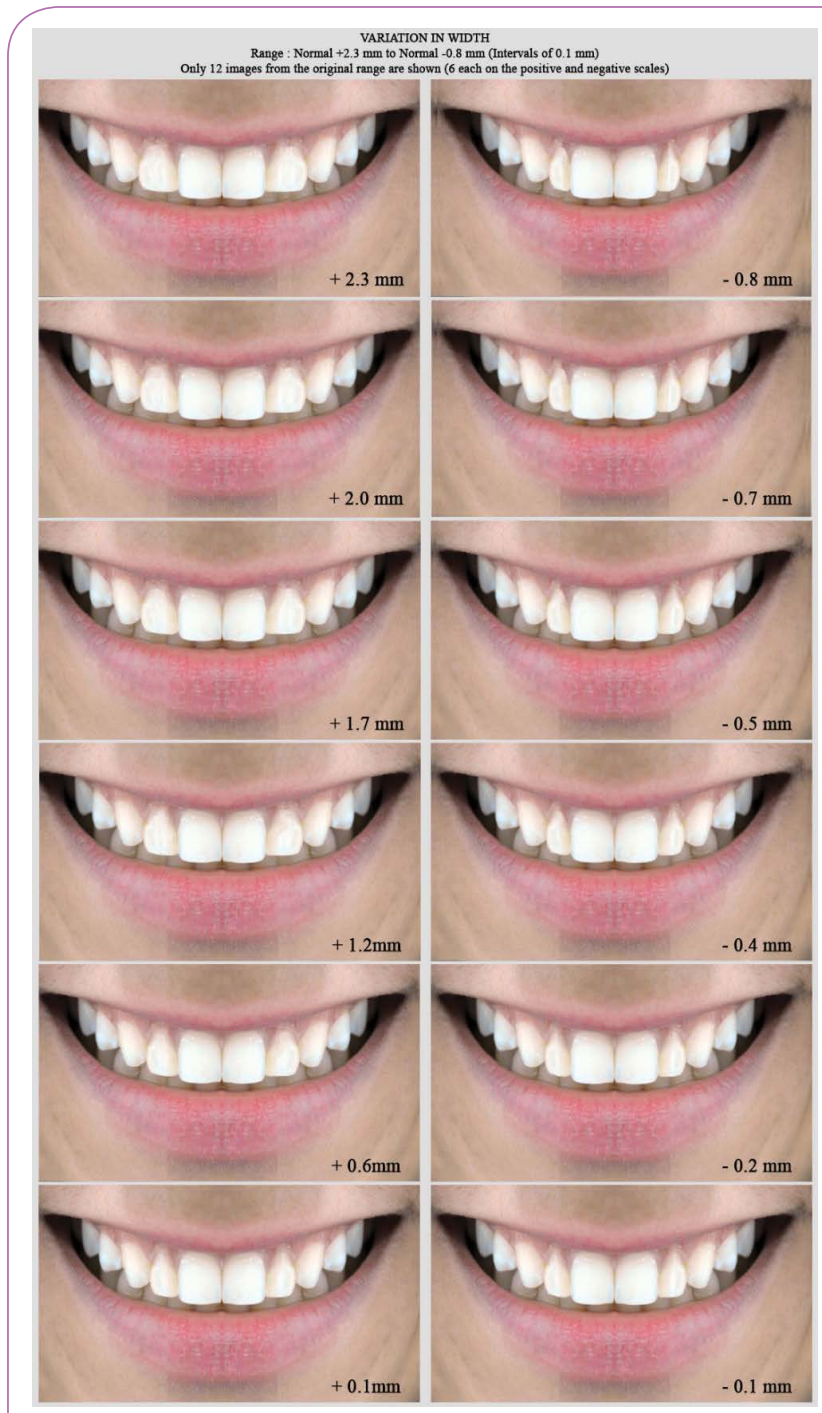

Figure 2 Sample of the pictures for Variation in Width of the lateral incisors (the pictures were presented to the patients in the form of a powerpoint slideshow with variations of $0.1 \mathrm{~mm}$ ). 


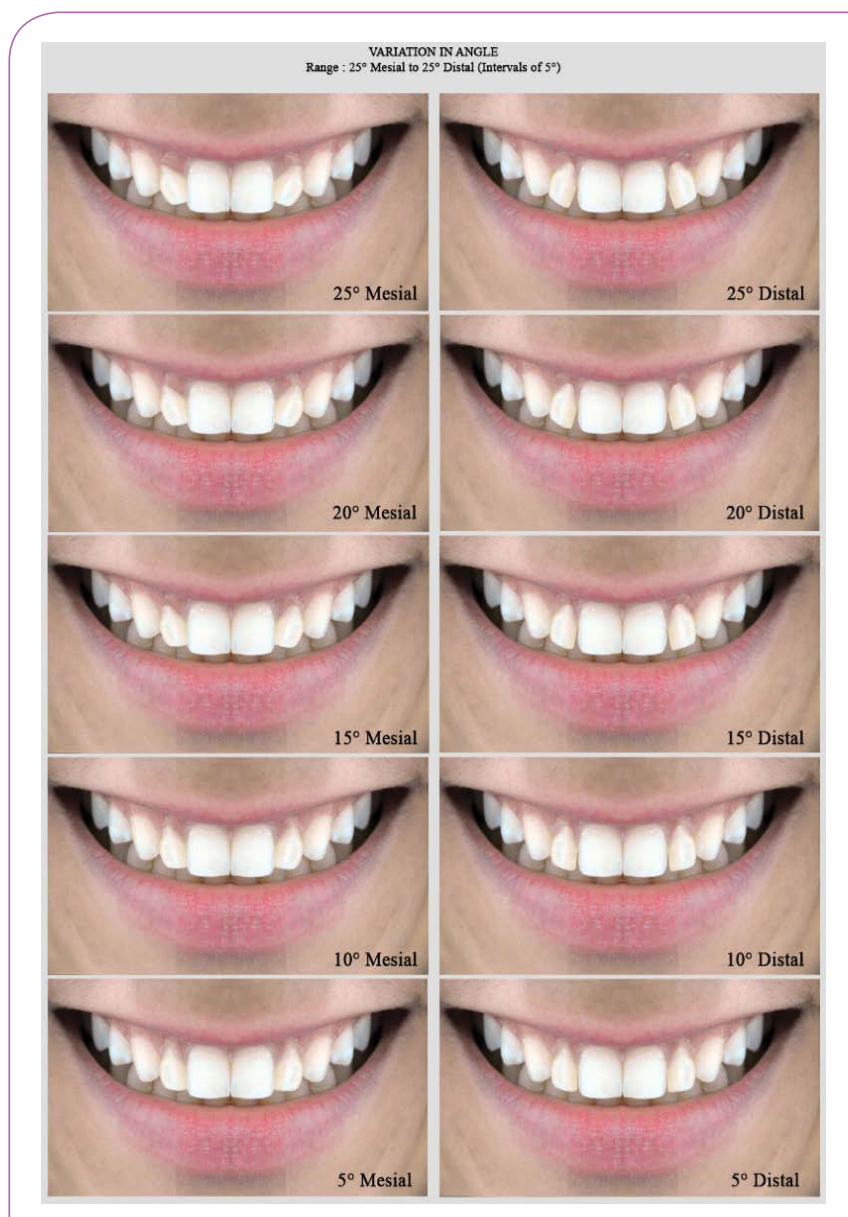

Figure 3 Pictures of the variation in angulation of the lateral incisor. 


\section{References}

1 Brunzel S, Kern M, Freitag S, Wolfart S (2006) Aesthetic effect of minor changes in incisor angulation: an internet evaluation. Journal of oral rehabilitation 33: 430-435.

2 King KL, Evans CA, Viana G, BeGole E, Obrez A (2008) Preferences for vertical position of the maxillary lateral incisors. World journal of orthodontics 9: 147-154.

3 Nikgoo A, Alavi K, Alavi K, Mirfazaelian (2009) A Assessment of the golden ratio in pleasing smiles. World journal of orthodontics 10 : 224-228.

4 Al-Habahbeh R, Al-Shammout R, Al-Jabrah O, Al-Omari F (2009) The effect of gender on tooth and gingival display in the anterior region at rest and during smiling. The European journal of esthetic dentistry: official journal of the European Academy of Esthetic Dentistry 4: 382395.

5 Wolfart S, Thormann H, Freitag S, Kern M (2005) Assessment of dental appearance following changes in incisor proportions. European journal of oral sciences 113: 159-165.

6 Bukhary SM, Gill DS, Tredwin CJ, Moles DR (2007) The influence of varying maxillary lateral incisor dimensions on perceived smile aesthetics. British dental journal 203: 687-693.

7 Hochman MN, Chu SJ, Tarnow DP (2012) Maxillary anterior papilla display during smiling: a clinical study of the interdental smile line. The International journal of periodontics \& restorative dentistry 32 : 375-383.

8 Machado AW, McComb RW, Moon W, Gandini LG (2013) Influence of the vertical position of maxillary central incisors on the perception of smile esthetics among orthodontists and laypersons. Journal of esthetic and restorative dentistry 25: 392-401.

9 Machado AW, Moon W, Gandini LG (2013) Influence of maxillary incisor edge asymmetries on the perception of smile esthetics among orthodontists and laypersons. American journal of orthodontics and dentofacial orthopaedics 143: 658-664.

10 Al Abdulwahhab B, Pani S, Al Khunaizi R, Al Faraj N (2013) Assessment of lip position preferences in a Saudi population using computer imaging. The European journal of esthetic dentistry: official journal of the European Academy of Esthetic Dentistry 8: 444-452.

11 De-Marchi LM, Pini NI, Ramos AL, Pascotto RC (2014) Smile attractiveness of patients treated for congenitally missing maxillary lateral incisors as rated by dentists, laypersons, and the patients themselves. The Journal of prosthetic dentistry 112: 540-546.

12 Alsulaimani FF, Batwa W (2013) Incisors' proportions in smile esthetics. Journal of orthodontic science 2: 109-112.

13 Brough E, Donaldson AN, Naini FB (2010) Canine substitution for missing maxillary lateral incisors: the influence of canine morphology, size, and shade on perceptions of smile attractiveness. American journal of orthodontics and dentofacial orthopaedics 138: 705e1-705e9.

14 Noureddine A, Fron Chabouis H, Parenton S, Lasserre JF (2014) Laypersons' esthetic perception of various computer-generated diastemas: a pilot study. The Journal of prosthetic dentistry 112 : 914-920.

15 Zarb GA, Bolender CL, Eckert S, Jacob R, Fenton A, Mericske-Stern R (2004) Prosthodontic treatment for edentulous patients. 12th edn. Complete dentures and implant-supported prostheses, St Louis: Mosby. 